\title{
Sleep quality and health in healthcare professionals fighting against COVID-19: a comparative study between high risk area (Hubei Province) and low risk area (Jiangsu Province) in China
}

Juan Li ( $\sim$ lijuanjr@126.com )

Second Military Medical University School of Nursing

Xiangjing Kong

Second Military Medical University School of Nursing

Fanfan Li

Suzhou Municipal Hospital

Bei Wu

New York University Rory Meyers College of Nursing

Hanzhang Xu

Duke University School of Nursing

Tian Wu

Suzhou Municipal Hospital

Jing Chu

Second Military Medical University School of Nursing

Jianmin Liu

Cerebral vascular disease Center, Changhai hospital affiliated to Second Military Medical University

\section{Research Article}

Keywords: sleep quality,health, healthcare professional, COVID-19

Posted Date: May 7th, 2020

DOI: https://doi.org/10.21203/rs.3.rs-27217/v1

License: () (1) This work is licensed under a Creative Commons Attribution 4.0 International License. Read Full License 


\section{Abstract}

Background: Novel Coronavirus Disease 2019 (COVID-19) emerged in Wuhan, Hubei Province, China in December 2019. Since then, there was an outbreak in Wuhan and the coronavirus spread quickly nationwide. Thousands of healthcare providers fought against COVID-19 in Wuhan and other areas of China. The present study aimed to investigate the levels and related factors of sleep quality of healthcare professionals fighting against COVID-19 in high risk area (Hubei Province) and low risk area (Jiangsu Province), and association between sleep quality and health.

Methods: A total of 253 healthcare professionals in Hubei Province $(n=119$, female $72.3 \%$, mean age $=32.13 \pm 5.50$, nurse $80.7 \%)$ and Jiangsu Province( $n=134$, female $94.0 \%$, mean age=30.2 \pm 5.52 , nurse $96.3 \%)$ were surveyed from February to March 2020. Sleep quality (Pittsburgh sleep quality index, PSQI) and health were assessed using an internet survey.

Results: The global PSQI score of Hubei sample and Jiangsu sample was $9.74 \pm 5.00$ and 7.79 \pm 4.64 , respectively. The global PSQI score and the scores of subjective sleep quality, sleep latency, sleep duration and use of sleep medications in Hubei sample were significantly higher than that of Jiangsu sample $(p<0.05)$. For Hubei sample, fear of infection, fatigue in Class 3 protection and worry about family were predictors of poor sleep quality $(\mathrm{OR}=5.020,95 \% \mathrm{Cl} 1.761-14.306, \mathrm{OR}=3.859,95 \% \mathrm{Cl} 1.168-12.753, \mathrm{OR}=3.576,95 \% \mathrm{Cl} 1.002-12.759$, respectively), while dizziness in Class 3 protection was predictor of poor sleep quality for Jiangsu sample $(\mathrm{OR}=7.063,95 \% \mathrm{Cl}$ 2.323-21.470). Poor sleep quality was associated with reduced self-reported health after controlling for covariates for all samples $(\beta=-0.75, p<0.01, \beta=-0.52, p<0.01$, respectively).

Conclusions: Sleep quality of healthcare professionals in Hubei was worse than that in Jiangsu. Poor sleep quality was associated to poor health. Our findings call for systematic sleep intervention program that are specially designed to help healthcare professionals fighting against infectious disease to improve their sleep quality.

\section{Background}

Novel Coronavirus Disease 2019 (COVID-19) emerged in Wuhan, Hubei Province, China in December 2019 [1]. Since then, there was an outbreak in Wuhan and the coronavirus spread quickly nationwide. The virus had high transmission capability and could cause high rate of case fatality $(2.3 \%)$ [1-4]. There had been 81,058 people infected by the virus and 3204 people died of the virus according to the report by March 14, 2020 [5]. Word Health Organization(WHO) declared that the COVID-19 was Public Health Emergency of International Concern (PHEIC\on January 30, 2020 [6]. Besides China, the coronavirus had been detected in 159 countries, areas or territories globally [7]. WHO called COVID-19 outbreak pandemic as virus spreads increasingly worldwide on March 11, 2020 [8]. With the increasing number of cases and widening geographical spread, the 2019 novel coronavirus disease (COVID-19) has been classified as one of the class B infectious diseases but prevented and controlled as class A infectious disease by the National Health Commission of China [9]. Due to lack of target drugs and vaccines, COVID-19 is considered to be a global threat to public health. Patients with COVID-19 in Wuhan accounted for the largest percentage among the total confirmed cases in China [1]. In order to cure patients infected by the coronavirus, Chinese government organized a panel of more than 300,000 healthcare professionals from other provinces of China to support Wuhan, Hubei Province and fought against COVID-19 since end of January, 2020 [9]. 
The transmission mode of COVID-19 seemed to be close person-to-person contact. The virus could be transmitted mostly by respiratory droplets [2]. Healthcare professionals confront high risk of infection because of close contact with patients [10]. They were under Tertiary biological protection with N95 masks, three pairs of gloves, shoulder cap, goggles, protective clothing, disposable surgical cap, visor, outer gown, boots and shoe covers [9]. As a result of growing number of patients diagnosed with COVID-19, healthcare professionals in Wuhan worked shift duties and underwent heavy load work and stress, which might predispose them to vulnerability to sleep disorders and health problem. According to the report of the Centers for Disease Control and Prevention(CDC), more than half healthcare professionals who were on night shift duties slept six hours or less than per day [11]. Sleep deficiency and poor sleep quality were associated with poor performance and reduced health status of healthcare professionals[12,13]. Out of Hubei Province, there were lots of healthcare professionals working in fever clinic, emergency, surgery room and infectious hospitals. They screened suspected patients, diagnosed, cured and cared the patients with COVID-19. Based on the special occupational environment and work load, the objective of this study was to investigate 1) the sleep quality of healthcare professionals fighting against COVID19 in high risk area (Hubei Province) and in low risk area (Jiangsu Province), and 2) the factors associated with sleep quality, and 3) the association between sleep quality and health status among healthcare professionals.

\section{Methods}

\section{Study design}

Cross-sectional study design conducted from February 29 to March 5, 2020.

\section{Participants}

Convenient sampling strategy was used. One hundred and thirty healthcare professionals working in Infectious Departments of Wuhan Maternal and Child health hospital Guanggu Branch and Jiangxia District First Hospital (located in Hubei Province) who were from Suzhou and Nanjing hospitals(located in Jiangsu Province) and one hundred and fifty healthcare professionals working in Suzhou and Nanjing hospitals were invited to complete selfadministered anonymous questionnaires. Finally, 253 healthcare professionals agreed to participate and completed the questionnaires using their smartphones on internet page of Wenjuanxing.com. Questionnaires were anonymous to guarantee confidentiality. The participating rate was $90.36 \%$.

\section{Measures}

Socio-demographic characteristics and work variables In the questionnaire, data about participants' sociodemographic characteristics and work variables were collected. Socio-demographic characteristics included age, gender, ethnicity, marital status and education. Work variables included occupation, years of working , work hours/day, number of shift work, work content and symptoms in work under Level 3 biological protection.

Sleep quality Sleep quality of the participants was assessed by Pittsburgh sleep quality index. It was a self-rating questionnaire for measuring subjective sleep quality[14]. The PSQI assessed seven sleep components: subjective sleep quality, sleep latency, sleep duration, habitual sleep efficiency, sleep disturbances, use of sleep medications, and daytime dysfunction. Seven component scores were summarized to yield a global PSQI score between 0 and 21 ; higher scores indicate worse sleep quality[14]. A global score $\mathbb{7} 7$ is generally indicating poor sleep quality in Chinese health adults[15]. 
Self-reported health status Health status was assessed with one item in the WHOQOL assessment, WHOQOLBREF. The item asked "How do you rate your health status at present?", and had five response categories that ranged from 1 (very poor) to 5 (very good)[16].

\section{Statistical analyses}

Descriptive statistics were used to summarize participants' socio-demographic characteristics, working variables, global score of PSQI and the score of seven sleep components and health status. Differences in the participants' characteristics, working variables, sleep quality and health status between Hubei and Jiangsu samples were evaluated with $t$ test for the continuous variables and with $\chi 2$ test for the categorical variables. Multivariable logistic regression was used to test the dependent variable (poor sleep quality coded as 1 versus good sleep quality coded as 0 ). The explanatory variables with possible relationship to poor sleep quality were sociodemographic characteristics and working variables. We conducted univariable logistic regression analyses first. We then included those variables that were significantly associated with the dependent variable $(p<0.05)$ in the multivariable logistic regression analyses. Odds ratios and $95 \%$ confidence intervals were reported. Multivariable linear regression was used to estimate the association between poor sleep quality and health. The analyses were conducted using the programs of SPSS version 22.0 (SPSS, Chicago, III, USA). Two-tailed $p$-values $<0.05$ were considered statistically significant.

\section{Results}

\section{Demographic characteristics of the participants}

Table 1 presents the participants' socio-demographic and working characteristics in Hubei Province and Jiangsu Province. For Hubei and Jiangsu samples, the average age was $32.13 \pm 5.50$ and $30.2 \pm 5.52$ and the percentage of female was $72.3 \%$ and $94.0 \%$. The majority of the healthcare professionals were nurses $(80.7 \%, 96.3 \%$, respectively). The average years of working was $9.84 \pm 5.32$ and $8.30 \pm 5.74$ and the average of working hours/day was $6.54 \pm 2.18$ and $8.81 \pm 2.24$, respectively for Hubei and Jiangsu samples. There were significantly differences in age, gender, marital status, education, occupation, working hours/day, number of shift work/week, job description and symptoms in work under Level 3 protection between Hubei and Jiangsu samples.

\section{The levels of sleep quality and self-reported health status}

Table 2 presents the participants' seven sleep component scores, global PSQI score, self-reported health status and self-reported factors related to sleep. The global PSQI score of Hubei sample and Jiangsu sample was $9.74 \pm 5.00$ and $7.79 \pm 4.64$, respectively. The global PSQI score and the score of subjective sleep quality, sleep latency, sleep duration and use of sleep medications in Hubei sample was significantly higher than that of Jiangsu sample $(p<0.05)$, which indicated that healthcare professionals in Hubei Province had poorer sleep quality than those in Jiangsu Province. The percentage of poor sleep quality (global PSQI >7) in Hubei sample was significantly higher than that of Jiangsu sample $(62.2 \%, 48.5 \%$, respectively, $p<0.05)$. The score of selfreported health of Hubei sample was lower than that of Jiangsu sample( $3.30 \pm 0.93,3.54 \pm 0.76$, respectively, $\mathrm{t}=-2.211, p<0.05$ ).

\section{Logistic regression model of factors associated with poor sleep quality}


Table 3 presents results of logistic regression of factors associated with poor sleep quality in Hubei and Jiangsu samples. For Hubei sample, healthcare professionals with fear of infection, fatigue in Class 3 protection and worry about family were more likely to have poor sleep quality $(\mathrm{OR}=5.020,95 \% \mathrm{Cl} 1.761-14.306, \mathrm{OR}=3.859,95 \% \mathrm{Cl} 1.168$ $12.753, \mathrm{OR}=3.576,95 \% \mathrm{Cl} 1.002-12.759$, respectively). For Jiangsu sample, healthcare professionals with dizziness in Class 3 protection were more likely to have poor sleep quality $(\mathrm{OR}=7.063,95 \% \mathrm{Cl} 2.323-21.470)$.

\section{Linear regression model between poor sleep quality and self-reported health}

Table 4 presents results of linear regression of association between poor sleep quality and self-reported health among healthcare professionals in Hubei and Jiangsu samples. Both for Hubei and Jiangsu samples, after controlling for other covariates, poor sleep quality was associated with reduced self-reported health status ( $\beta=-0.75, p<0.01, \beta=-0.52, p<0.01$, respectively).

\section{Discussion}

The study examined sleep quality and health status among healthcare professionals fighting against COVID-19 in high risk area (Hubei Province) and low risk area (Jiangsu Province). The sleep quality of healthcare professionals in Hubei Province and Jiangsu Province were both poor, and sleep quality of Hubei sample was worse than that of Jiangsu sample. The related factors of poor sleep quality between Hubei and Jiangsu samples were different. Fear of infection, fatigue in Class 3 protection and worry about family were predictors of poor sleep quality for Hubei sample, while dizziness in Class 3 protection was a predictor of poor sleep quality for Jiangsu sample. Poor sleep quality was significantly associated with poor self-reported health status after controlling for other covariates both for Hubei and Jiangsu samples. These findings add new evidence to the association between sleep quality and health status among healthcare professionals. Our findings support that poor sleep quality among healthcare professionals fighting against COVID-19 was a concern that the management staffs should pay more attention to healthcare professionals' sleep quality. More supportive strategies are needed to improve the sleep quality of healthcare professionals fight against COVID-19.

The scores of PSQI among healthcare professionals fight against COVID-19 in present study were higher than that of Chinese healthy adults (3.88 \pm 2.52$)$ [15]. They were also higher than the average level of sleep quality of healthcare professionals in Hunan Province and Guangzhou Province, China $[17,18]$. Previous studies had demonstrated that healthcare professionals working on night shift had higher global PSQI score than those working on day shift or rotating shift $[19,20]$. The score of PSQI among Jiangsu sample was similar to that of healthcare professionals working on night shift in Guangzhou Province, China and Spain [18, 19]. However, the score of PSQI among Hubei sample was higher than that of healthcare professionals working on night shift [19, 20], which indicated that healthcare professionals fighting against COVID-19 in Hubei Province had poorer sleep quality than other healthcare professionals.

The healthcare professionals in Hubei Province had poorer sleep quality than those in Jiangsu Province. It was consistent with the results of previous studies conducted during Severe Acute Respiratory Syndrome (SARS) or Middle East Respiratory Syndrome (MERS) outbreak. Previous study showed that more healthcare workers from SARS isolation units with high-risk exposure to SARS in Hong Kong, China in 2003 reported sleep deprivation, fatigue, worry about health, and fear of social contact, compared to those from psychiatric inpatient units with low-risk exposure [21, 22]. Nurses working in SARS units and SARS Intensive Care Unit (ICU) during the peak SARS outbreak in Taiwan, China reported higher rate of insomnia than those working in non-SARS units, and the nurses 
working in SARS units had the poorest sleep quality (PSQI 6.5 \pm 0.4 ) compared to those working in non-SARS units. Healthcare workers who performed MERS related tasks during outbreak of MERS in Korea reported significantly higher level of post-traumatic stress disorder and poor sleep quality than those who performed non-MERS related tasks [23]. According to the Chinese CDC's report, the percentage of accumulated patients diagnosed with COVID19 in Hubei Province among Chinese total patients was $74.7 \%$ by February 11 , and the percentage rose to $83.6 \%$ by March 16, $2020[1,5]$. Due to the person-to-person transmission mode, healthcare professionals working in Hubei Province were considered at high risk of exposure because they were the front-line workers for thousands of patients with COVID-19, while healthcare professionals working in Jiangsu Province were considered at low risk of exposure. This may partially explain the difference of sleep quality between the Hubei sample and Jiangsu sample.

The predictors of poor sleep quality between Hubei and Jiangsu healthcare professionals were different. For Hubei sample, fear of infection, fatigue in Class 3 protection and worry about family were predictors of poor sleep quality, while dizziness in Class 3 protection was a predictor of poor sleep quality for Jiangsu sample. When confronted with a newly emerging infectious disease (COVID-19), healthcare professionals often felt fearful, especially the transmission and treatment strategies for COVID-19 were still being determined. When a disease caused deaths among healthcare workers, they became terrified. According to the Chinese CDC' report, there had been 3019 healthcare professionals infected by the COVID-19 and 5 healthcare professionals died of COVID-19 by February 12, 2020 [10]. It was because the transmission mode of COVID-19 was not clear at the beginning of outbreak and many healthcare professionals contacted the patients with COVID without any efficient biological protection. It was evident that during 2003 SARS outbreak, medical staff were working under extremely stressful conditions and had strong emotional reactions like fear, restlessness, anger or frustration, according to a survey of Canadian medical staff [24]. Healthcare professionals in Hubei Province in present study worked in isolation wards and cared the patients with COVID-19. Although they were under Class 3 biological protection, they still had risk of being infected because of close contact with patients. So fear of infection was associated with poor sleep quality for Hubei sample. For Jiangsu sample, healthcare professionals were at low-risk of contact with patients with COVID-19. Thus, fear of infection was not a predictor of poor sleep quality in Jiangsu healthcare professionals. Fatigue and dizziness in Class 3 protection were predictors of poor sleep quality for the Hubei and Jiangsu sample, respectively. Healthcare professionals under Class 3 protection often experienced mild anoxia, dizziness, sweating and fatigue. Previous study has showed that workers with work-related physical fatigue were more likely to have insomnia [25]. The healthcare professionals in Hubei sample were from hospitals in Jiangsu Province. They set off to Wuhan, Hubei Province to help cure the patients with COVID-19 in late of January and beginning of February 2020. The working and living environment was unfamiliar for them. They worked on shift duties and kept hospital-dormitory routine every day. They were far from families. They could communicate with families by Wechat or telephone at off time, however, they usually hid their stress, fatigue and risk of infection before their families. On the other hand, they couldn't take care of families and they often felt worried about families, which might be related to poor sleep quality.

\section{Limitations and strengths}

The strengths of our study include a comparative study design that enable us to investigate levels and related factors of sleep quality among healthcare professionals fighting against COVID-19 in high risk area (Hubei Province) and low risk area (Jiangsu Province) in China. However, the COVID-19 outbreak in 2019 imposed limitations on present study. Healthcare professionals worked on heavy load, thus, the questionnaire had to be 
brief, self-administered and anonymous [26]. It encouraged healthcare professionals' participation and minimized stigma [27]. Considering the healthcare professionals fighting against COVID-19 often felt tired after work, we limited the items of questionnaire and we didn't collect the information about stress, coping strategy and social support, which may be related to sleep quality. So the association between stress, coping, social support and sleep quality was not explored. This study used convenient sampling strategy and it may have selective bias. The conclusion should be interpreted with caution.

\section{Clinical implications}

Our findings showed that sleep quality of healthcare professionals in Hubei Province and Jiangsu Province were both poor, and sleep quality of Hubei sample was worse than that of Jiangsu sample. Poor sleep quality was significantly associated with poor self-reported health status for all samples. These finding call for more attention paid to healthcare professionals' sleep quality. The American Academy of Nursing recommends that health care service and standard-setting organizations implement policies that promote the sleep health of nurses [28]. The findings may provide useful information for managers to develop a systematic sleep intervention program, which is specially designed for healthcare professionals fighting against an infectious disease outbreak. The intervention program would be beneficial to the improvement of sleep quality and health status of healthcare professionals. However, we understand that healthcare professionals in fighting against COVID-19 had experienced poor-quality sleep during the days caring patients with the coronavirus. They need psychological intervention and emotional support just in time. If systematic intervention programs could be set up as contingency plans before an infectious disease outbreak, the healthcare professionals could receive training and support before or at the beginning of outbreak, then the healthcare professionals may cope more efficiently and less experienced poor-quality sleep and health status.

\section{Conclusion}

This is the first comparative study reporting levels and related factors of sleep quality and the association between sleep quality and health status among healthcare professionals fighting against COVID-19 in a high risk area (Hubei Province) and a low risk area (Jiangsu Province) in China. We found that sleep quality of healthcare professionals in high risk area was worse than that in low risk area. Poor sleep quality was significantly associated with poor self-reported health status. The findings suggested that sleep quality of healthcare professionals working in the front line is a concern when an infectious disease outbreaks, which calls for effective intervention programs. In future studies, establishing systematic sleep intervention programs for healthcare professionals fighting against infectious disease and exploring the effect of the intervention are needed.

\section{Abbreviations}

COVID-19: Novel Coronavirus Disease 2019; PSQI: Pittsburgh sleep quality index; WHO: Word Health Organization; PHEIC: Public Health Emergency of International Concern; CDC: Centers for Disease Control and Prevention; IRB: Institutional Review Board; SARS: Severe Acute Respiratory Syndrome; MERS: Middle East Respiratory Syndrome.

\section{Declarations}

\section{Acknowledgments}


We thank all of the healthcare professionals participated in this study for their courage and support in the fighting against COVID-19.

Author's contributions $\mathrm{JL}$ designed the concept, analyzed and interpreted data, and prepared the manuscript. BW and $\mathrm{HX}$ reviewed the manuscript. JML and JC designed the concept and reviewed the manuscript. XK, FL and TW collected the data.

Funding This study was supported by the funding from Naval Medical University Nursing Discipline Talent Training Program (18QPBJ06) and Shanghai Pujiang Program (18PJC115) .

\section{Availability of data and materials}

The data is available upon individual request to Dr. Juan Li at lijuanjr@126.com.

\section{Ethics approval}

The study was approved by the Institutional Review Board (IRB) of Naval Medical University(HJEC-2020-LW-001).

\section{Consent for publication}

Not applicable

\section{Competing interests}

None declared.

\section{Author details}

1 Second Military Medical University, School of Nursing, Shanghai, China

2 Cerebral vascular disease Center, Changhai hospital affiliated to Second Military Medical University, Shanghai, China

3 Air Force Hospital of Eastern Theater Command, Nanjing, China

4 Suzhou Municipal Hospital, Suzhou, China.

5 University Rory Meyers College of Nursing, New York, NY, United States

6 Duke University School of Nursing, Durham, NC, United States

7 Duke University School of Medicine, Durham, NC, United States

The study was approved by the Institutional Review Board (IRB) of Naval Medical University(HJEC-2020-LW-001) and all the participants provided written informed consent.

\section{References}

1. Novel Coronavirus Pneumonia Emergency Response Epidemiology Team. The epidemiological characteristics of an outbreak of 2019 novel coronavirus diseases (COVID-19) in China. Zhonghua liu xing bing xue za zhi. 
2020;41:145-51. doi:10.3760/cma.j.issn.0254-6450.2020.02.003.

2. Li Q, Guan X, Wu P, Wang X, Zhou L, Tong Y, et al. Early Transmission Dynamics in Wuhan, China, of Novel Coronavirus-Infected Pneumonia. N Engl J Med. 2020;:1-9.

3. Chen N, Zhou M, Dong X, Qu J, Gong F, Han Y, et al. Epidemiological and clinical characteristics of 99 cases of 2019 novel coronavirus pneumonia in Wuhan, China: a descriptive study. Lancet. 2020;395:507-13. doi:10.1016/S0140-6736(20)30211-7.

4. Phelan AL, Katz R, Gostin LO. The Novel Coronavirus Originating in Wuhan, China: Challenges for Global Health Governance. JAMA - J Am Med Assoc. 2020;323:709-10.

5. Chinese Center of Disease Prevention and Control. Cases distribution of COVID-19. http://2019ncov.chinacdc.cn/2019-nCoV/.

6. World Health Organization. Corona- virus disease (COVID-19) outbreak. https://www.who.int/.

7. World Health Organization. Novel coronavirus(COVID-19) Situation. https://experience.arcgis.com/experience/685d0ace521648f8a5beeeee1b9125cd.

8. World Health Organization. COVID-19 as a pandemic. https://www.who.int.

9. National Health Commission of the the People's Republic of China. Notice on the guideline of prevention and control techniques for COVID-19 in medical institutions (Version 1).

10. Xinhua News Agency. COVID-19 has been confirmed person-to-person transmission. Healthcare workers have been infected. http://www.xinhuanet.com/2020-01/20/c_1125487200.htm\%0A.

11. Prevention the $C$ for $D C$ and. Short sleep duration among workers--United States, 2010. MMWR. 2012;61:2815.

12. Silva-Costa A, Griep RH, Rotenberg L. Disentangling the effects of insomnia and night work on cardiovascular diseases: A study in nursing professionals. Brazilian J Med Biol Res. 2015;48:120-7.

13. Caruso CC, Baldwin CM, Berger A, Chasens ER, Landis C, Redeker NS, et al. Position statement: Reducing fatigue associated with sleep deficiency and work hours in nurses. Nurs Outlook. 2017;65:766-8. doi:10.1016/j.outlook.2017.10.011.

14. Buysse DJ, Reynolds CF, Monk TH, Berman SR, Kupfer DJ. The Pittsburgh Sleep Quality Index: a new instrument for psychiatric practice and research. Psychiatry Res. 1989;28:193-213.

15. Liu X. Reliability and validity of the the Pittsburgh sleep quality index. Chinese Psychiatr J. 1996;29:103-7.

16. Skevington SM, Lotfy M, O'Connell $\mathrm{K}$ a. The World Health Organization's WHOQOL-BREF quality of life assessment: psychometric properties and results of the international field trial. A report from the WHOQOL group. Qual Life Res. 2004;13:299-310. doi:10.1097/01.AOG.0000157207.95680.6d.

17. Liu J. Study on depresion, anxiety, sleep quality and influencing factors of medical staff in a third. Nanhua University; 2018.

18. Qiuzhen T, Xiaoning C, Xuemei W. The sleep quality, daytime function and life quality of medical staff with shift work in Panyu. China Mod Dr. 2013;51:135-6.

19. Gomez-Garcia T, Ruzafa-Martinez M, Fuentelsaz-Gallego C, Madrid JA, Rol MA, Martinez-Madrid MJ, et al. Nurses' sleep quality, work environment and quality of care in the Spanish National Health System: Observational study among different shifts. BMJ Open. 2016;6:1-11.

20. Dai C, Qiu H, Huang Q, Hu P, Hong X, Tu J, et al. The effect of night shift on sleep quality and depressive symptoms among Chinese nurses. Neuropsychiatr Dis Treat. 2019;15:435-40. 
21. McAlonan GM, Lee AM, Cheung V, Cheung C, Tsang KWT, Sham PC, et al. Immediate and sustained psychological impact of an emerging infectious disease outbreak on health care workers. Can J Psychiatry. 2007;52:241-7.

22. Su TP, Lien TC, Yang CY, Su YL, Wang JH, Tsai SL, et al. Prevalence of psychiatric morbidity and psychological adaptation of the nurses in a structured SARS caring unit during outbreak: A prospective and periodic assessment study in Taiwan. J Psychiatr Res. 2007;41:119-30.

23. Lee SM, Kang WS, Cho AR, Kim T, Park JK. Psychological impact of the 2015 MERS outbreak on hospital workers and quarantined hemodialysis patients. Compr Psychiatry. 2018;87:123-7. doi:10.1016/j.comppsych.2018.10.003.

24. Maunder R, Hunter J, Vincent L, Bennett J, Peladeau N, Leszcz M, et al. The immediate psychological and occupational impact of the 2003 SARS outbreak in a teaching hospital. Cmaj. 2003;168:1245-51.

25. Schjelderup SE, Lund NTI, Knut H, Jarle MP. Physical work exposure, chronic musculoskeletal pain and risk of insomnia: Iongitudinal data from the HUNT study, Norway. Occup Env Med. 2018;75:421-6.

26. Chua SE, Cheung V, Cheung C, McAlonan GM, Wong JWS, Cheung EPT, et al. Psychological effects of the SARS outbreak in Hong Kong on high-risk health care workers. Can J Psychiatry. 2004;49:391-3.

27. Bai YM, Lin CC, Lin CY, Chen JY, Chue CM, Chou P. Survey of stress reactions among health care workers involved with the SARS outbreak. Psychiatr Serv. 2004;55:1055-7.

28. Caruso CC, Baldwin CM, Berger A, Chasens ER, Edmonson JC, Gobel BH, et al. Policy brief: Nurse fatigue, sleep, and health, and ensuring patient and public safety. Nurs Outlook. 2019;67:615-9.

\section{Tables}

Table 1 Demographic and work characteristics of healthcare professionals in Hubei and Jiangsu 


\begin{tabular}{|c|c|c|c|c|c|}
\hline$\overline{\text { les }}$ & $\begin{array}{l}\text { Total sample } \\
(\mathrm{N}=253)\end{array}$ & $\begin{array}{c}\text { Hubei sample } \\
\square \mathrm{n}=119 \square\end{array}$ & $\begin{array}{c}\text { Jiangsu sample } \\
\square \mathrm{n}=134 \square\end{array}$ & $x^{2} / \mathrm{t}$ & $\mathrm{p}$ \\
\hline & $31.15 \pm 5.58$ & $32.13 \pm 5.50$ & $30.2 \pm 5.52$ & 2.69 & 0.008 \\
\hline \multicolumn{6}{|l|}{$\mathrm{r}$} \\
\hline 3 & $41 \square 16.2 \% \square$ & 33ロ27.7\%॰ & $8 \square 6 \% \square$ & 21.98 & 0.000 \\
\hline ale & 212₫83.8\%ם & 86ロ72.3\%॰ & $126 \square 94.0 \% \square$ & & \\
\hline ity - Han & 251₫99.2\%ם & $118 \square 99.2 \% \square$ & 133ロ99.3\%॰ & 0.007 & 0.933 \\
\hline 1 status - Married & $170 \square 67.2 \% \square$ & $90 \square 75.6 \% \square$ & $80 \square 59.7 \% \square$ & 7.26 & 0.007 \\
\hline \multicolumn{6}{|l|}{ tion } \\
\hline oma & $53 \square 20.9 \% \square$ & $15 \square 12.6 \% \square$ & $38 \square 28.4 \% \square$ & 15.42 & 0.000 \\
\hline relor & 184ロ72.7ロ & 91प76.5\%匹 & 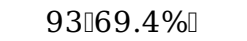 & & \\
\hline ter/doctor & $16 \square 6.3 \% \square$ & $13 \square 10.9 \% \square$ & 3๑2.2\%口 & & \\
\hline \multicolumn{6}{|l|}{ ation } \\
\hline tor & 28ロ11.1】 & 23ロ19.3\%॰ & $5 \square 3.7 \% \square$ & 15.58 & 0.000 \\
\hline se & \multicolumn{4}{|c|}{ of working } & \\
\hline J1 WOIKIIIY & $74 \square 29.2 \% \square$ & $29 \llbracket 24.4 \% \square$ & $45 \square 33.6 \% \square$ & 4.66 & 0.098 \\
\hline \multirow[t]{2}{*}{1} & 99๑39.1\%॰ & 45॰37.8\%॰ & $54 \square 40.3 \% \square$ & & \\
\hline & $80 \square 31.6 \% \square$ & $45 \square 37.8 \% \square$ & $35 \square 26.1 \% \square$ & & \\
\hline \multicolumn{6}{|l|}{ lours/day } \\
\hline 1 & $72 \square 28.5 \% \square$ & 67૧56.3\%॰ & $5 \square 3.7 \% \square$ & 89.40 & 0.000 \\
\hline $3 \mathrm{~h}$ & $135 \square 53.4 \% \square$ & 38॰31.9\%॰ & 97૧72.4\%॰ & & \\
\hline $10 \mathrm{~h}$ & $16 \square 6.3 \% \square$ & $8 \square 6.7 \% \square$ & $8 \square 6.0 \% \square$ & & \\
\hline h & $30 \square 11.9 \% \square$ & $6 \square 5.0 \% \square$ & $24 \square 17.9 \% \square$ & & \\
\hline \multicolumn{6}{|l|}{ week } \\
\hline shifts & $2.79 \pm 2.51$ & $2.39 \pm 2.11$ & $3.14 \pm 2.79$ & -3.03 & 0.004 \\
\hline Ig shifts & $0.83 \pm 0.98$ & $1.13 \pm 0.89$ & $0.57 \pm 0.96$ & 4.67 & 0.000 \\
\hline it shifts & $1.39 \pm 1.44$ & $1.56 \pm 1.21$ & $1.23 \pm 1.60$ & 2.13 & 0.034 \\
\hline \multicolumn{6}{|l|}{;ontent } \\
\hline ening/diagnosis/management & 207๑81.8\%ロ & $110 \square 92.4 \% \square$ & 97ロ72.4\%॰ & 17.03 & 0.000 \\
\hline y life caring & $163 \square 64.5 \% \square$ & $85 \square 71.4 \% \square$ & $78 \square 58.2 \% \square$ & 4.81 & 0.028 \\
\hline tional support & $160 \square 63.2 \% \square$ & $89 \square 74.8 \% \square$ & $71 \square 53 \% \square$ & 12.89 & 0.000 \\
\hline nfecting wards & $147 \square 58.1 \% \square$ & $80 \square 67.2 \% \square$ & $67 \square 50.0 \%$ & 7.68 & 0.006 \\
\hline ning the wards & $100 \square 39.5 \% \square$ & $66 \square 55.5 \% \square$ & $34 \square 25.4 \% \square$ & 23.87 & 0.000 \\
\hline $\begin{array}{l}\text { ying protective clothing and } \\
\text { es }\end{array}$ & $97 \square 38.3 \% \square$ & $67 \square 56.3 \% \square$ & $30 \square 22.4 \% \square$ & 30.66 & 0.000 \\
\hline onstruction of ward environment & $77 \square 30.4 \% \square$ & $46 \square 38.7 \% \square$ & $31 \square 23.1 \% \square$ & 7.17 & 0.007 \\
\hline \multirow{2}{*}{\multicolumn{6}{|c|}{ oms in work under Level 3}} \\
\hline & & & & & \\
\hline st distress & $128 \square 50.6 \% \square$ & $59 \square 49.6 \% \square$ & $34 \square 25.4 \% \square$ & 3298 & 0.000 \\
\hline ating & $116 \square 45.8 \% \square$ & $77 \square 64.7 \% \square$ & $39 \square 27.1 \% \square$ & 32.18 & 0.000 \\
\hline iness & $93 \square 36.8 \% \square$ & $59 \square 49.6 \% \square$ & $34 \square 25.4 \% \square$ & 15.88 & 0.000 \\
\hline yue & $61 \square 24.1 \% \square$ & $38 \square 31.9 \% \square$ & $23 \square 17.2 \% \square$ & 7.513 & 0.006 \\
\hline tness of breath & $71 \square 28.1 \% \square$ & $55 \square 46.2 \% \square$ & $16 \square 11.9 \% \square$ & 36.68 & 0.000 \\
\hline itation & $63 \square 24.9 \% \square$ & $48 \square 40.3 \% \square$ & $15 \square 11.2 \% \square$ & 28.62 & 0.000 \\
\hline sea & $46 \square 18.2 \% \square$ & $38 \square 31.9 \% \square$ & $8 \square 6.0 \%$ & 28.56 & 0.000 \\
\hline iting & $8 \square 3.2 \% \square$ & $6 \square 5.0 \% \square$ & $2 \square 1.5 \%$ & 2.59 & 0.107 \\
\hline ring difficulty & $62(24.5 \%)$ & $46(38.7 \%)$ & $16(11.9 \%)$ & 24.31 & 0.000 \\
\hline
\end{tabular}

Table 2 Sleep Quality and self-reported health of healthcare professionals 


\begin{tabular}{|c|c|c|c|c|c|}
\hline iables & Total sample $(\mathrm{N}=253)$ & Hubei sample $\llbracket n=119 \square$ & Jiangsu sample $\llbracket n=134 \square$ & $\mathrm{t} / \mathrm{x}^{2}$ & $\mathrm{p}$ \\
\hline jective sleep quality & $1.22 \pm 0.74$ & $1.42 \pm 0.78$ & $1.04 \pm 0.65$ & 4.260 & 0.000 \\
\hline sp latency & $2.63 \pm 1.82$ & $2.90 \pm 1.85$ & $2.40 \pm 1.76$ & 2.216 & 0.028 \\
\hline p duration & $1.17 \pm 0.87$ & $1.34 \pm 0.83$ & $1.01 \pm 0.88$ & 3.066 & 0.002 \\
\hline itual sleep efficiency & $0.65 \pm 0.95$ & $0.72 \pm 1.02$ & $0.58 \pm 0.89$ & 1.079 & 0.282 \\
\hline p disturbances & $1.10 \pm 0.61$ & $1.13 \pm 0.62$ & $1.08 \pm 0.60$ & 0.573 & 0.567 \\
\hline of sleep medications & $0.24 \pm 0.66$ & $0.42 \pm 0.85$ & $0.09 \pm 0.38$ & 3.979 & 0.000 \\
\hline time dysfunction & $1.69 \pm 1.43$ & $1.78 \pm 1.41$ & $1.60 \pm 1.45$ & 1.023 & 0.307 \\
\hline 2I score & $8.70 \pm 4.90$ & $9.74 \pm 5.00$ & $7.79 \pm 4.64$ & 3.205 & 0.002 \\
\hline Ereported health & $3.43 \pm 0.85$ & $3.30 \pm 0.93$ & $3.54 \pm 0.76$ & -2.211 & 0.028 \\
\hline r sleep quality & 139ロ54.9\%ם & $74 \square 62.2 \% \square$ & $65 \square 48.5 \% \square$ & 4.763 & 0.029 \\
\hline \multicolumn{6}{|l|}{$\begin{array}{l}\text { Ereported factors related to } \\
\text { p }\end{array}$} \\
\hline Tental stress & $160 \square 63.2 \% \square$ & 89ロ74.8\%ロ & $71 \square 53 \% \square$ & 12.89 & 0.329 \\
\hline hysical fatigue & 113ロ44.7\%ם & $57 \square 47.9 \% \square$ & $56(41.8 \%)$ & 0.95 & 0.871 \\
\hline Joise of sleeping environment & 97ロ38.3\%ロ & $45 \square 37.8 \% \square$ & $52 \square 38.8 \% \square$ & 0.03 & 0.048 \\
\hline Vorry about family & $77 \square 30.4 \% \square$ & $29 \square 24.4 \% \square$ & $48 \square 35.8 \% \square$ & 3.90 & 0.000 \\
\hline ear of infection & $67 \square 26.5 \% \square$ & $51 \square 42.9 \% \square$ & $16 \square 11.9 \% \square$ & 30.94 & 0.019 \\
\hline motional exhaustion & $21 \square 8.3 \% \square$ & $15 \square 12.6 \% \square$ & $6 \square 4.5 \% \square$ & 5.47 & 0.000 \\
\hline
\end{tabular}

Table 3 Logistic regression of factors associated with poor sleep quality in Hubei and Jiangsu samples

\begin{tabular}{|c|c|c|c|c|c|c|c|c|c|c|c|c|}
\hline \multirow{4}{*}{$\begin{array}{l}\text { Variables } \\
\text { dizziness }\end{array}$} & \multicolumn{6}{|c|}{ Hubei sample } & \multicolumn{6}{|c|}{ Jiangsu sample } \\
\hline & \multicolumn{3}{|c|}{ Univariable analyses } & \multicolumn{3}{|c|}{ Multivariable analyses } & \multicolumn{3}{|c|}{ Univariable analyses } & \multicolumn{3}{|c|}{ Multivariable analyses } \\
\hline & \multirow{2}{*}{$\frac{\mathrm{OR}}{3.44^{* *}}$} & \multicolumn{2}{|c|}{$95 \% \mathrm{CI}$} & \multirow{2}{*}{$\frac{\mathrm{OR}}{1.780}$} & \multicolumn{2}{|l|}{$95 \% \mathrm{CI}$} & \multirow{2}{*}{$\frac{\mathrm{OR}}{10.31^{* * *}}$} & \multicolumn{2}{|c|}{$95 \% \mathrm{CI}$} & \multirow{2}{*}{$\frac{\mathrm{OR}}{7.063^{* *}}$} & \multicolumn{2}{|l|}{$95 \% \mathrm{CI}$} \\
\hline & & 1.57 & 7.53 & & 0.645 & 4.911 & & 3.67 & 28.97 & & 2.323 & 21.470 \\
\hline Chest & & & & 1.298 & 0.434 & 3.882 & & & & 1.950 & 0.790 & 4.813 \\
\hline distress & $2.90 *$ & 1.29 & 6.50 & & & & $3.588^{* *}$ & 1.67 & 7.68 & & & \\
\hline Palpitation & 1.88 & 0.86 & 4.10 & 0.700 & 0.228 & 2.147 & $4.98^{*}$ & 1.34 & 18.57 & 1.313 & 0.254 & 6.795 \\
\hline $\begin{array}{l}\text { Hearing } \\
\text { difficulty }\end{array}$ & $2.34^{*}$ & 1.05 & 5.22 & 1.468 & 0.550 & 3.918 & 2.61 & 0.85 & 7.98 & 1.581 & 0.417 & 6.001 \\
\hline Fatigue in & & & & $3.859 *$ & 1.168 & 12.753 & & & & .932 & 0.300 & 2.897 \\
\hline Class 3 & & & & & & & & & & & & \\
\hline protection & $4.95^{* *}$ & 1.87 & 13.13 & & & & 1.48 & 0.60 & 3.65 & & & \\
\hline $\begin{array}{l}\text { Mental } \\
\text { stress }\end{array}$ & $2.36^{*}$ & 1.02 & 5.50 & 2.064 & 0.717 & 5.942 & $2.22 *$ & 1.11 & 4.44 & 1.695 & 0.781 & 3.679 \\
\hline Fear of & & & & $5.020 * *$ & 1.761 & 14.306 & & & & .908 & 0.233 & 3.533 \\
\hline infection & $7.96^{* * *}$ & 3.14 & 20.18 & & & & 1.91 & 0.65 & 5.59 & & & \\
\hline Worry & & & & $3.576^{*}$ & 1.002 & 12.759 & & & & 1.219 & 0.513 & 2.898 \\
\hline about & & & & & & & & & & & & \\
\hline family & $5.23 * *$ & 1.68 & 16.26 & & & & 1.85 & 0.91 & 3.79 & & & \\
\hline
\end{tabular}

Notes. CI confidence interval, OR odds ratio. ${ }^{*} \mathrm{p}<.05 .{ }^{* *} \mathrm{p}<.01 .{ }^{* * *} \mathrm{p}<.001$

Table 4 Linear regression of self-reported health of healthcare professionals in Hubei and Jiangsu samples 


\begin{tabular}{|c|c|c|c|c|c|c|c|c|c|c|c|c|}
\hline \multirow{3}{*}{ Variables } & \multicolumn{6}{|c|}{ Hubei sample } & \multicolumn{6}{|c|}{ Jiangsu sample } \\
\hline & \multicolumn{3}{|c|}{$\begin{array}{c}\text { Univariable } \\
\text { analyses }\end{array}$} & \multicolumn{3}{|c|}{ Multivariable analyses } & \multicolumn{3}{|c|}{ Univariable analyses } & \multicolumn{3}{|c|}{ Multivariable analyses } \\
\hline & B & $\mathrm{SD}$ & $\mathrm{p}$ & B & $\mathrm{SD}$ & $\mathrm{p}$ & B & $\mathrm{SD}$ & $\mathrm{p}$ & B & $\mathrm{SD}$ & $\mathrm{p}$ \\
\hline $\begin{array}{l}\text { Poor sleep } \\
\text { quality }\end{array}$ & -0.91 & 0.15 & 0.000 & -0.75 & 0.16 & 0.000 & -0.60 & 0.12 & 0.000 & -0.52 & 0.13 & 0.000 \\
\hline occupation & -0.21 & 0.21 & 0.323 & -0.13 & 0.18 & 0.484 & 0.69 & 0.34 & 0.047 & 0.612 & 0.32 & 0.059 \\
\hline Work hours/day & -0.13 & 0.04 & 0.001 & -0.11 & 0.03 & 0.001 & -0.03 & 0.03 & 0.403 & -0.022 & 0.03 & 0.413 \\
\hline dizziness & -0.26 & 0.17 & 0.120 & 0.03 & 0.16 & 0.874 & -0.33 & 0.149 & 0.031 & 0.092 & 0.17 & 0.604 \\
\hline Nausea & -0.25 & 0.18 & 0.169 & -0.02 & 0.17 & 0.906 & -0.70 & 0.27 & 0.011 & -0.342 & 0.30 & 0.259 \\
\hline Vomiting & -1.02 & 0.38 & 0.008 & -0.89 & 0.34 & 0.010 & -1.05 & 0.54 & 0.052 & -0.51 & 0.57 & 0.378 \\
\hline Palpitation & -0.30 & 0.17 & 0.085 & -0.25 & 0.16 & 0.118 & -0.53 & 0.21 & 0.011 & -0.40 & 0.21 & 0.057 \\
\hline
\end{tabular}

